\title{
Entre a moral, a ciência e a doutrina: os discursos educacionais e a profissão docente
}

Between morality, science and doctrine: educational discourses and the teaching profession

Entre la moral, la ciencia y la doctrina: los discursos educativos y la profesión docente

\section{RENATA MARCílio CÂNDIDO ${ }^{1}$; ARLINDO DA SILVA LOURENÇO ${ }^{2}$}

\section{Resumo}

O artigo analisa os discursos veiculados pela Revista de Ensino (1902-1918), especialmente, aqueles relacionados à formação e à identidade dos professores, comparando-os aos da grande mídia produzidos a partir do que se convencionou chamar de "Escola sem Partido", no início deste século. Trata-se de um relato de pesquisa fundamentado em estudiosos da área que almeja retomar como se definiram as características relacionadas à docência num contexto considerado fundamental para a constituição do campo educacional paulista: finais do século XIX e início do XX, e das temáticas que figurariam como definidoras dos debates na área pelos anos seguintes. Organizaram-se os textos selecionados em categorias de análise relacionadas às características profissionais e pessoais dos professores e as formas pelas quais deveriam compreender e atuar no âmbito do ensino. As análises empreendidas revelam o discurso dual e ambíguo definidor da profissão, ora apresentada como um sacerdócio, ora fundamentando sua profissionalização nos métodos científicos.

Palavras-chave: Profissão Docente; História da Educação; Escola sem Partido.

\footnotetext{
${ }^{1}$ Doutora em Educação pela Faculdade de Educação da Universidade de São Paulo. Professora da Universidade Federal de São Paulo. E-mail: remarcilio@gmail.com

${ }^{2}$ Doutor em Psicologia Social pelo Instituto de Psicologia da Universidade de São Paulo (USP). Pesquisador do Laboratório de Estudos sobre o Preconceito da USP. E-mail: arlindolourenco@uol.com.br
} 


\begin{abstract}
The article analyzes the discourses of the Revista de Ensino (1902-1918), especially those related to the formation and identity of teachers, comparing them to those of the mainstream media produced from what has been called the "School without Party" at the beginning of this century. This article is a report of research based on scholars in the area who intends to retake how the characteristics related to teaching were defined in a context considered fundamental for the constitution of the educational field of São Paulo: late nineteenth and early twentieth centuries, and themes that would appear as defining to the debates in the area for the following years. The selected texts were organized into categories of analysis related to the professional and personal characteristics of the teachers and the ways in which they should understand and act in the teaching context. The analysis carried out reveals the ambiguous discourse that defines the profession, at times presented as priesthood, and other times basing its professionalization on scientific methods.
\end{abstract}

Keywords: teaching profession; history of education; school without party.

\title{
Resumen
}

El artículo analiza los discursos informados en la Revista de Ensino (1902-1918), en especial aquellos relacionados a la formación y la identidad de los profesores, comparándolos a los de los grandes medios producidos a partir de lo que se convenció llamar "Escola sem Partido", a principios de este siglo. Se trata de un relato de investigación fundamentado en estudiosos del área que anhela revivir como se definieron las características concernidas a la docencia en un contexto estimado fundamental para la constitución del campo del educación en São Paulo: finales del siglo XIX e inicio del XX, y de las asuntos que figurarían como definitorias de los debates en el área por los años siguientes. Se organizaron los textos seleccionados en clases de análisis referidas con las calidades profesionales y personales de los educadores y las formas en que deberían comprender y actuar en el ámbito de la enseñanza. Los análisis emprendidos revelan el discurso dual y ambiguo declarante de la profesión, ora presentada tal un sacerdocio, ora asentando su profesionalización en los métodos científicos.

Palabras clave: Profesión docente; historia de la educación; Escuela sin partido. 
O presente artigo retoma e analisa os discursos veiculados em um periódico especializado em educação: a Revista de Ensino, órgão oficial da Associação Beneficente do Professorado Público de São Paulo ${ }^{3}$, que circulou no campo educacional entre os anos de 1902 e 1918. A Revista de Ensino, desde seu primeiro exemplar, comprometeu-se com os interesses da instrução e com os direitos do professorado; de modo abrangente apresentava discussões sobre questões gerais às quais o professor não podia, no seu parecer, estar alheio, como por exemplo, debates sobre a elaboração das leis concernentes à instrução pública; fornecimento de material e orientação à prática docente; informação e divulgação de críticas sobre obras didáticas; além da defesa dos direitos do professorado. Ademais, foi também um importante veículo divulgador dos esforços da Associação para concretizar suas propostas iniciais de defesa, assistência e aprimoramento intelectual do professorado (CATANI, 1989).

A importância do estudo dos periódicos educacionais consiste no fato de constituírem "um excelente observatório" do movimento do campo educacional em diferentes contextos sócio históricos (CATANI, 1989), ao permitirem conhecer as formas de estruturação do campo educacional, o movimento docente e a organização das escolas em diferentes períodos da história brasileira. Nóvoa (1997) reitera a relevância do estudo dos periódicos educacionais para a investigação histórica ao justificar o seu projeto de criação de um repertório analítico da imprensa de educação e ensino em Portugal. Para o autor, a imprensa é o melhor meio para apreender a pluralidade do campo educativo, pois revela as múltiplas facetas dos processos educativos, tanto numa perspectiva interna (cursos, programas, currículos) quanto externa (papel desempenhado pelas famílias e por outras instâncias de socialização) ao sistema de ensino; além disso, as informações por ela fornecidas permitem reflexões muito próximas do acontecimento, possibilitando relacionar as orientações emanadas do Estado e as práticas efetivas de sala de aula. Por fim, constitui-se como o lugar de afirmação de um grupo e de uma permanente regulação coletiva.

A Revista de Ensino circulou durante o Primeiro Período da República Brasileira, momento no qual se acentuou a preocupação com as questões educacionais. Nesse contexto, a democracia, a federação e a educação constituíram-se elementos imprescindíveis para, tal como se afirmava, empreender-se a "salvação" do país. No discurso dominante, a educação seria a solução de todos os problemas sociais, econômicos e políticos por ser regeneradora do homem e da sociedade. A escola foi concebida, nesse contexto de institucionalização da nova ordem política, como um marco sinalizador da ruptura com o passado (CARVALHO, 1989).

Esta preocupação com o setor educacional foi traduzida principalmente na realização de reformas educacionais; criação de escolas; investimento dos homens públicos no setor educacional; formação de professores; preocupação com a eficiência dos métodos pedagógicos. Devido a essa movimentação no campo educacional, Catani (1989) explica que o primeiro decênio da República será relembrado com nostalgia pelos educadores da época como "período áureo".

Todas estas questões presentes no ideário republicano puderam ser vislumbradas nos discursos selecionados que constituem o corpus deste artigo. Ao todo foram selecionados discursos, conferências e palestras, que tratavam de temas bastante diversificados proferidos em ocasiões distintas. Cabe destacar que, embora na sua transcrição recebessem os títulos variados

\footnotetext{
${ }^{3}$ Parte das discussões aqui apresentadas foi retomada de trabalho enviado e aprovado para apresentação no VI Congresso Luso-Brasileiro de História da Educação.
} 
acima indicados, nem a organização interna dos textos, nem os conteúdos abordados nos permitiram perceber diferenças conceituais que justificassem sua divisão em três grupos distintos.

Dentre os discursos selecionados, destacaram-se alguns temas recorrentes que foram organizados em três grandes blocos de análise: a presença de metáforas, destacando-se as de filiação cristã, para definir o trabalho e a carreira docente, bem como a ambiguidade discursiva resultante disso em relação à luta da categoria por melhores condições de trabalho; as questões relativas à finalidade da educação e à educação moral e cívica das crianças e da sociedade; a ciência como única propulsora legítima do progresso da educação e da Pátria; e por fím alguns discursos que 'destoaram' deste corpus principalmente pelos indivíduos que os formularam e os conteúdos abordados.

\section{O professor-apóstolo e as dualidades discursivas sobre a educação pública}

Como mostra Scheffler (1974), as metáforas são, freqüentemente, componentes fundamentais das teorias científicas. Porém, ao contrário destas, não se desenvolvem cumulativamente, tampouco estão presas a processos experimentais de predição ou confirmação. Sugerindo paralelos significativos entre dois eventos ou processos, podem também veicular programas - sempre através de analogias. Toda metáfora possui limitações, justamente os pontos em que as analogias entram em colapso. Isso não é razão para rejeitá-las por completo, contudo indicar esses limites é imprescindível para analisá-las criticamente. Tal análise deve, além disso, verificar se as analogias sugeridas são, no contexto de sua elocução, desprovidas ou não de importância.

Ainda segundo o autor, os programas veiculados por asserções metafóricas precisam ser avaliados independentemente. Tais programas buscam canalizar a ação em contextos práticos, em que a finalidade da analogia é enunciar pretensas verdades sobre o fenômeno em jogo. Uma vez que as questões de política social tomam forma exatamente quando escolhas alternativas de ações são possíveis, é preciso discernir se o programa proposto por uma metáfora é ou não moralmente desejável. Finalmente, comparar metáforas alternativas não apenas indica o "caráter plurifacetado do objeto", como abre novas possibilidades para o pensamento e a ação.

Encontramos metáforas em cerca de metade dos discursos analisados. Recorrentes em todo o período do estudo, referem-se principalmente ao professor e à prática docente. Sempre correlatas a essas, e não tão freqüentes, ocorrem algumas relativas ao aluno, à escola, ao saber. Em menor número, e sem ligação com aquelas, as referentes aos "grandes homens". Nos dois primeiros casos, podemos organizá-las em dois grandes grupos de significações, um tributário da Arte, outro do Cristianismo. Este, além de agrupar mais metáforas e de ser o mais recorrente, possui grande importância devido às implicações de seu conteúdo programático para a organização e fortalecimento do professorado. Foi por isso privilegiado em nossa análise.

A docência não é caracterizada somente como missão: é também ministério e sacerdócio. Mais do que isso: apostolado. O professor, um sacerdote, pastor, evangelizador, apóstolo - seu modelo deve ser, nas palavras de D. Maria Reis (nov., 1907)4 " “os apóstolos de Cristo”, ou o próprio

\footnotetext{
${ }^{4}$ Nas referências relacionadas à Revista de Ensino optamos por apresentar apenas o mês e o ano da publicação a fim de melhorar a legibilidade do texto, as páginas dos artigos variam conforme encadernação do periódico consultado em diferentes acervos.
} 
"Divino Mestre", como quer João Lourenço Rodrigues (mar., 1914). Os alunos constituem seu rebanho, o saber é hóstia santa e luminoso evangelho do templo ou luminoso recinto que é a escola. Sendo Cristo o grande modelo, não estranhamos que os adjetivos usados para qualificar as vicissitudes do trabalho docente sejam sempre dois: nobre, espinhoso. A coroa de espinhos retrata as dificuldades do trabalho, "senda de espinhos e escabrosidades" (ainda que intercalada de flores) para Antonio Alves Aranha (jun., 1907) ou "mar com escolhos" (mar., 1904); a dignidade com que foi usada indica a postura esperada dos professores nas adversidades.

As metáforas cristãs que retratam a docência como apostolado ressaltam a importância que assume, para aqueles que a exercem, a convicção de que aquilo que ensinam é indispensável para os alunos. Não apenas para os seus, mas para todos os alunos. De fato, um professor que não crê na relevância daquilo que ensina para a vida de seus alunos está, no mínimo, a meio caminho do fracasso. Os problemas dessa analogia começam na distinção entre o "aquilo" da religião e do ensino laico. No primeiro caso, temos verdades reveladas - incontestáveis, portanto, para aqueles que têm fé. No segundo, sejam ciências, artes ou mesmo costumes, temos sempre verdades convencionadas, provisórias - que convivem, muitas vezes, com verdades concorrentes. Tratar os conhecimentos escolares como dogmas implica confundir a educação escolar com doutrinação. A escola como templo padece dos mesmos problemas: não se entra num templo para discutir, e sim para afirmar a fé. Também é importante notar que a proximidade com os termos de matriz cristã modifica os sentidos dos termos derivados da "luz": se estes, num primeiro momento, remetem ao Iluminismo e ao poder iluminador da razão, aqui essas mesmas luzes adquirem uma áurea sagrada. No "luminoso recinto" da escola republicana paulista podemos perceber os ecos da crença em Cristo como caminho, verdade e luz.

O professor como apóstolo encontra limites semelhantes: afinal, ele não testemunha nem propaga uma verdade revelada. Contudo o colapso da analogia é, neste caso, ainda maior: a finalidade da vida dos apóstolos de Cristo era exatamente o testemunho e a difusão das palavras do mestre. Os martírios sofridos, apenas um preâmbulo para a grande recompensa após a morte. Mesmo para o mais idealista dos professores, a única certeza possível é a de viver de acordo com os próprios ideais. A comparação com o sacerdócio pode ser ainda mais radical: esquece que um sacerdote está, por mais fé que tenha e dificuldades que encontre, materialmente amparado pela ordem a que pertence. Quanto aos alunos como rebanho, devemos lembrar que ovelhas não são humanas, jamais o serão - por melhor guiadas que sejam. Um pastor as protege, e isso é tudo.

Proferidos e publicados durante os dois primeiros decênios do século XX, os discursos analisados se inserem num contexto histórico de consolidação e fortalecimento dos ideais republicanos. Entende-se, portanto, a ênfase que se procura dar aos professores como "sacerdotes do ideal da instrução", como quer D. Paulina Nacarado (mar., 1908); bem como da necessidade de "apostolizar a causa grandiosa da civilização" no dizer de João Lourenço Rodrigues (jun., 1904). Afinal, a difusão da Instrução Pública é considerada estratégica para a formação de cidadãos identificados com o novo regime.

Entretanto, não deixa de ser paradoxal que os discursos em questão tenham sido publicados na revista da Associação Beneficente do Professorado Público de São Paulo - que é, aliás, para Arthur Breves (ago., 1904) uma "jóia engastada na coroa de espinhos do professorado paulista". A utilização de metáforas de filiação cristã cria uma dualidade tanto na análise da situação do magistério, quanto nas ações propostas para modificá-la. Desse modo, 
embora sejam abundantes as críticas aos baixos salários, às condições precárias de muitas escolas, à falta de comprometimento do Estado com a educação pública; as metáforas sugerem a aceitação dos fatos e a manutenção do entusiasmo pelos professores apesar das dificuldades. Com isso, a reivindicação de melhores condições de trabalho é sempre relegada ao segundo plano: o principal é manter, como quer João Kopke (mar., 1910), uma "dedicação desinteressada" devido à "santidade do sacerdócio".

O programa veiculado por tais asserções metafóricas, portanto, é contrário ao fortalecimento do próprio associativismo. Isso porque a ação proposta é, em última instância, individual: cabe a cada professor-apóstolo aceitar com dignidade os espinhos inerentes à sua nobre missão, jamais perdendo de vista a importância crucial de seu trabalho para a glória da Pátria. Assim, independentemente do valor que possam ter essas analogias para a compreensão da importância do ensino público nos primórdios da República, não podemos deixar de criticar seu conteúdo programático. Ele contribui, afinal, para manter inalterada a situação do magistério, mesmo porque, como afirma Oscar Brisolla (dez., 1915) o professor já conhecia, antes de assumi-lo, "o pesado burel de nosso amargo sacerdócio".

O outro grupo de metáforas identifica o professor como primoroso artífice, cinzelador, lapidador, grande artista. Os alunos são argila para D. Maria Reis (nov., 1907) ou "preciosas gemas" nas palavras de Ramon Roca Dordal (dez. 1911). Em sua análise das analogias entre o ensino e o fazer artístico, Scheffler (1974) mostra que destacam o fato de, nos dois casos, a idéia inicial poder ser modificada pelo próprio processo. No entanto, desconsideram que os alunos continuam a se desenvolver após o fim do trabalho do professor-artista. Além disso, os objetivos docentes não são sujeitos a padrões estéticos, e sim a considerações de ordem moral e prática.

\section{A formação escolar e a moralização dos cidadãos: o papel do professor}

Uma das tarefas consideradas primordiais na "missão do professor" era a formação do caráter dos educandos, entendida como formação moral do bom cidadão e da boa mãe. Neste sentido, cabe retomarmos a elocução de José Feliciano de Oliveira (1903), que representa de forma exemplar a opinião de grande parte dos educadores cujos discursos sobre esse tema foram registrados nas páginas da Revista de Ensino. Nas palavras daquele professor, o verdadeiro sentido da educação é justamente a formação dos cidadãos, sendo o civismo o mais alargado sentimento social, que formará a "simpatia universal" e a união dos povos. "Ser um bom cidadão é a maneira mais decisiva de ser um bom homem, um homem social" (fev., 1903, grifo do autor). Cabe aos educadores encaminhar metodicamente o espírito dos alunos, fortalecendolhes a vontade até a formação do cidadão exemplar.

A ruptura social produzida pela Proclamação da República no Brasil tornou necessária a constituição de um novo universo simbólico capaz de atribuir legitimidade ao regime político que se instaurava. É neste momento que se recorre a valores cívicos e símbolos nacionais para tentar evitar a desintegração da ordem social. A escola pública republicana se fundava não só como o lugar onde se ensinavam e se aprendiam tais valores, mas como instituição guardiã dos mesmos cuja ação moral e pedagógica deveria se estender para toda a sociedade (SOUZA, 2000). 
Várias atividades do âmbito escolar foram perpassadas pelo ensino do civismo, como por exemplo, as aulas de história; os rituais de hasteamento da bandeira nacional; os hinos pátrios aprendidos nas aulas de música e apresentados em ocasiões solenes; as festas comemorativas de eventos ou de homenagens aos heróis nacionais. No projeto nacionalista vigente, a escola constitui-se como instituição fundamental para transformar "o caboclo, o imigrante e o operário em cidadãos brasileiros” (BITTENCOURT, 1988, p.45). Tais ações possuíam como objetivos representar e celebrar a identidade e soberania do Brasil independente, incentivar o 'sentimento republicano' do povo, consolidar um modelo de escola pública, estatal e laica e configurar uma cultura escolar, permitindo que a escola tivesse maior visibilidade social e reforçasse sentidos culturais comuns (SOUZA, 2000).

Os exemplos do mestre, dos alunos, bem como dos grandes nomes da história do Brasil também serviam ao ensino do civismo e da moralidade. Era por este motivo que a profissão de mestre não poderia ser exercida por todos, já que estes deveriam ser um modelo de conduta exemplar aos seus “discípulos”. Carlos A. Gomes Cardim (1908), então inspetor de ensino, afirma que em todos os atos dos alunos percebe-se sempre o reflexo do mestre, porque este "pela sugestão, incute-lhe todas as qualidades que possui" (mar., 1908). Por outro lado, um mau mestre representa um "perigo social de conseqüências desastrosíssimas", influenciando seus alunos que, em seu convívio imediato, tornam-se verdadeiros "veículo de propaganda" das qualidades "deploráveis do seu mau guia”. Desse modo, segundo o autor, é possível perceber, a partir da observação do comportamento das crianças, as qualidades e defeitos do seu mestre. Além de ser um exemplo de boa conduta, um bom professor, segundo Dino Bueno (1906), é aquele que pratica sua "missão" com amor, já que este é o princípio criador de todas as coisas, inclusive de homens para a sociedade.

Com relação aos exemplos advindos das ações de outros alunos, destacou-se o discurso de Coelho Neto (1916) na comemoração cívica da festa da bandeira, ocasião na qual o aluno Antonio Chagas foi premiado com uma medalha por ter salvado o nosso estandarte de um naufrágio. Coelho Neto rememora detalhadamente o acontecido e o momento que o garoto no meio do mar volta ao barco para buscar a bandeira, descreve sua ação como um ato de coragem e patriotismo, um verdadeiro exemplo que deveria servir tanto aos seus colegas quando às pessoas mais velhas (professores e pais presentes na solenidade). Para o autor, venerar a bandeira é venerar os limites geográficos de uma nação.

Foi premente em certos discursos a preocupação com a crise moral que, segundo alguns autores, ameaçava a sociedade e a escola. De acordo com João Lourenço Rodrigues (1904), essa crise se assinalava principalmente no domínio especulativo do ceticismo, pela inconsistência das opiniões e das doutrinas, pelo desterro do entusiasmo e pela ausência de idealismo representado no pessimismo - considerado como a mais terrível epidemia moral da época. O professor, na sua "sagrada missão", deveria resguardar a escola infantil com uma vigilância sempre desperta para que seus alunos não se contaminassem com esta epidemia, educando e instruindo ao mesmo tempo, já que "Não basta instruir; quem instrui, sem despertar o espírito, sem aprimorar-lhe as faculdades, constrói sobre a areia...” (jun., 1904). A educação moral, segundo este autor, deve ser o preâmbulo obrigatório de todo sistema educativo, e só poderia ser alcançada com o auxílio da família, considerada como um elemento imprescindível para o sucesso do ensino. Também na opinião da professora Maria Reis (nov., 1907) a educação será sempre defeituosa sem a cooperação da família. 
A formação de um corpo são em uma alma forte, nobre, franca e verdadeira constituíam o objetivo final dos processos educativos no contexto analisado. O ideal de bom cidadão deveria saber os preceitos para bem cuidar da sua saúde e da sua moral. Era tarefa do educador "incutir" nas crianças hábitos saudáveis como um dos "primeiros deveres humanos", e demonstrar que é um verdadeiro pecado físico desprezar ou prejudicar a saúde "pela infração dos preceitos de higiene", conforme Dino Bueno (mar., 1906). Neste sentido, cabe destacarmos outros discursos que retomam esta preocupação com a saúde e higiene das crianças, em que a escola era percebida como a responsável pela disseminação da higiene na sociedade. O professor deveria velar pela saúde das "criancinhas", Mario Mandelli (dez., 1916) chega mesmo a dizer que o professor deveria assumir o cargo de médico, estudando e aplicando conhecimentos específicos da área quando esse não existisse na escola.

Faz-se relevante lembrar que esta preocupação com a disseminação dos preceitos higiênicos e da sua relação com o contexto social e escolar já estava presente no debate social desde o período Imperial Brasileiro, no qual, como explica Gondra (2000), a medicina começou a se preocupar com os problemas da ordem social, incluindo-se a questão da formação das novas gerações. Ela definia seu papel pedagógico pela necessidade da difusão de um saber e de uma verdade que fundamentariam a ação coordenada de toda a sociedade. A educação escolar, neste contexto, deveria ser ordenada de modo a concretizar o projeto de erradicação da ignorância e de produção de um futuro ordeiro, homogêneo e civilizado de uma sociedade higienizada.

Em síntese, o civismo, a moral e a higiene concorriam na escola para a formação de um verdadeiro cidadão, capaz de fazer progredir o país. Entretanto, como advertem certas alocuções, a constituição da nação republicana também dependia da disseminação de escolas por todas as regiões do país, pois não seria possível formar verdadeiros cidadãos enquanto o analfabetismo ainda não houvesse desaparecido, enquanto cada indivíduo não conhecesse seus direitos e deveres.

\section{Ciência e progresso: as novas Bandeiras paulistas}

Ao estudar a disseminação dos procedimentos disciplinares na sociedade ocidental moderna, Foucault (1984) mostra que essa nova tecnologia do poder define redes hierárquicas precisas como estratégia para controlar as forças formadas numa multiplicidade organizada. Ao organizarem instituições, as disciplinas permitem não só o crescimento de poder, como a constituição de novos conhecimentos. Estes possibilitam, por sua vez, a multiplicação dos efeitos de poder.

Essa imbricação entre saber e poder pode ser observada no processo de constituição do campo educacional em São Paulo. Queremos destacar justamente a ênfase dada, em grande parte dos discursos publicados na Revista de Ensino, à importância do domínio dos novos conhecimentos científicos relacionados à criança pelos professores - não só para elevar o prestígio profissional como, principalmente, para assegurar o progresso e a grandeza da Pátria. Se tais conhecimentos já faziam parte da formação dos professores nas Escolas Normais, era ainda preciso garantir a adesão aos novos métodos. Ao contrário das metáforas educacionais, cuja utilização se distribui de modo equilibrado durante todo o período estudado, percebemos que o destaque dado à ciência como propulsora do progresso na educação pública acentua-se 
no segundo decênio da publicação. Assim, Ramon Roca Dordal (dez., 1911) destaca a necessidade do professorado acompanhar os progressos na "arte de ensinar". A propósito disso, Luiz Felipe Gonzalez (jun., 1914) lembra que se a Pedagogia, como muitas outras ciências, começou por ser arte, necessitava agora de "investigações rigorosamente exatas", ressaltando a importância das escolas experimentais.

Guilherme Kuhlmann (dez., 1914) afirma que, sendo a escola o "centro da evolução social", o ensino precisa ser racional, "baseado nos princípios da psico-fisiologia". O "conhecimento completo das bases científicas dos métodos de ensino" alargam os conhecimentos do professor, evidenciam seu intelecto e aumentam-lhe, portanto a dignidade. Essas bases científicas são identificadas com os estudos acerca do desenvolvimento físico e psíquico da criança. Para ele, o engrandecimento da instrução pública só seria possível através de sua homogeneização nessa "marcha progressiva" do ensino. João Kopke (mar., 1910) e Carlos Escobar (set., 1911) fazem a defesa do método analítico de leitura em detrimento do sintético embasando-se em dados científicos. Paradoxalmente, pouco importa que os antigos tenham tido sucesso na alfabetização - sucesso, aliás, que é minimizado - eles o faziam partindo de pressupostos equivocados. Em nenhum momento coloca-se a possibilidade do fracasso com o uso do novo método. Consideramos pertinente notar que essa crença nos poderes dos métodos de ensino fundamentados nas mais recentes descobertas científicas sobre o desenvolvimento infantil - pois se trata, exatamente, de crença, infensa a simples observação sensata do real permanece forte nos discursos educacionais de hoje. Quase cem anos depois, continua-se a creditar o fracasso ao desconhecimento (ou aplicação incorreta) de novos métodos de ensino, e a menosprezar sucessos que não sejam naqueles fundamentados.

O problema da falta de uniformidade na atuação dos grupos escolares era creditado ao seu isolamento e desarticulação por João Lourenço Rodrigues (set., 1907). Como medidas para modificar essa situação, ele propõe a ampliação da ação da Escola-Modelo, que deveria ser o paradigma do ensino paulista, bem como a publicação de um anuário de ensino e a elaboração de programas mais detalhados. Além da busca dessa uniformização do ensino público em São Paulo, encontramos os desejos de sua expansão para os outros estados brasileiros. Theodoro de Morais (dez., 1911) afirma que cabe ao ensino paulista servir à causa da civilização do Brasil. Para Oscar Brisolla (dez. 1915) a superioridade de São Paulo sobre os outros estados, enfraquecidos pelo analfabetismo, devia-se exatamente à ação dos professores primários, "herdeiros legítimos das Bandeiras" que então se deslocavam por todo país para reorganizar as escolas. São Paulo é descrita como "terra clássica da liberdade", "donde têm partido as mais nobres e formosas iniciativas" e donde há de partir o "gérmen fecundante da regeneração da nação". Essa ênfase nas qualidades superiores dos paulistas já estava presente no discurso do Dr. Alfredo Nascimento publicado em duas partes (dez. 1903 e fev. 1904), no qual apresenta uma releitura da história do Brasil que localiza no "Sul" (leia-se São Paulo/Minas Gerais) o "centro da verdadeira nacionalidade" durante a colonização, e vê no paulista o "elemento pátrio" por excelência.

Finalmente, consideramos importante apontar que, se José Feliciano (jun., 1908) critica a pretensa superioridade da "raça" branca e defendia a igual educabilidade de todas as "raças" humanas, Carlos Escobar (set., 1911) respondia à questão do avanço na aprendizagem da leitura por uma minoria de alunos utilizando, além da crítica aos métodos arcaicos de ensino, o argumento então científico da diferença das "raças" no que se refere à configuração do "sistema 
nervoso". Isso não implicava em recusa a educar os "inferiores", ao contrário: a mesma ciência mostrava que as aptidões para aprender, desde que corretamente exercitadas, crescem de uma geração para outra. Porém, uma vez que instruir é "formar estruturas nervosas", não se pode esperar o mesmo desempenho de alunos de "raças" diferentes. Um dos perigos de justificar escolhas políticas em argumentos científicos é esquecer que os critérios desses dois campos de ação são diferentes: no caso da política, o que deve validar a ação são considerações de ordem prática e moral (SCHEFFLER, 1974). Outro perigo é esquecer que a ciência, não sendo verdade revelada, está sujeita a alterações periódicas: as teorias eugenistas que embasavam o discurso de Carlos Escobar já não possuem a menor credibilidade científica.

\section{Os discursos destoantes: a voz das mulheres e os elogios ao período imperial}

De todos os discursos publicados somente dois foram proferidos por mulheres, um pela professora D. Maria Reis (1907) em novembro de 1907 por ocasião da inauguração do Grupo Escolar de São Simão e outro pela professora Paulina Nacarato (1908) pronunciado por ocasião da formatura dos professores complementaristas de 1907. No primeiro discurso D. Maria Reis tece elogios a iniciativa do Estado de abrir mais uma escola, um "luminoso recinto" para as "criancinhas, que se acham famintas desse pão que nutre a inteligência" (nov., de 1907). Entretanto, critica a ausência de presenças ilustres nesta ocasião ao relembrar que "nos tempos de antigamente" compareciam personagens como Cesário Motta, Bernardino de Campo, dentre outros, e denomina este período como o momento áureo, como tempos heróicos da instrução em São Paulo. Nas suas palavras finais dirigidas aos professores deixa explícita a sua crítica ao modelo escolar em vigor, pede aos professores: "Trabalhe, como o fazeis agora, dando realce e vida a instituição moribunda, e a uma classe de funcionários do Estado, que há dilatado prazo se vê órfão das carícias paternais" (nov., de 1907). Críticas incisivas como essa apresentada no discurso de D. Maria Reis não eram comuns nos artigos publicados, que geralmente deixavam implícito as dificuldades do trabalho do professor e seu pouco reconhecimento social.

Por sua vez, o discurso da professora Paulina Nacarato, pronunciado por ocasião da formatura dos professores complementaristas de 1907, fez-se relevante pela análise engendrada sobre a história do professorado público paulista. Ela divide essa história em dois momentos que se assinalam por um contraste de uma "incisão cruel". O primeiro período considerado áureo seria aquele referente ao primeiro decênio republicano, caracterizado pela organização escolar e regulamentação engendradas por "grandes homens", como Caetano de Campos e Cesário Motta. Em seguida viria o período de abatimento, mas não por causa do professorado que teria perdido seu "amor" pelo ensino, mas sim por parte dos Governos nos quais faltaram elementos de entusiasmo e estímulo. E finaliza afirmando que naquele momento estava acontecendo um "despertar do torpor" graças ao Sr. Gustavo de Godoy, recém-empossado Secretário do Interior, que estava "revivificando o entusiasmo entre os professores". Estes discursos se destacam por dois motivos, primeiro pelo fato de terem sido pronunciados por professoras e em segundo lugar por apresentarem críticas tão incisivas sobre o sistema de ensino paulista. Neste sentido, como afirma Nóvoa (1997) a importância do estudo dos periódicos também se dá pelo fato de que muitas vozes só puderam se fazer ouvir através desses, já que não possuíam acesso a outros meios de divulgação de pensamento, como talvez fosse o caso destes discursos proferidos por mulheres. 
O segundo aspecto percebido nos discursos denominados "destoantes" diz respeito aos conteúdos que veiculavam, no caso, elogios ao período Imperial. Neste sentido, acreditamos ser importante destacar que o Dr. Alfredo Nascimento (fev., 1904), em seu panorama sobre a história do Brasil do descobrimento à República, atribui a D. Pedro II um "patriotismo real e inato", e ao seu reinado, período de franca prosperidade, "quase tudo" que se fez de "quanto o Brasil hoje apresenta como nação civilizada". Lembra que, então, ainda pouco se escrevera sobre os fatos do final do segundo império e sobre a nova fase republicana, em que o Brasil, "com a espada de Deodoro, apontou para um outro alvo e avançou resoluto a caminho de seu futuro". "E qual será esse futuro?...", é a frase que encerra seu discurso. Surpreendeu-nos positivamente sua publicação numa revista francamente comprometida com os ideais republicanos.

Destacamos, também, a análise lúcida de João Lourenço Rodrigues (dez., 1914) sobre os débitos da Escola Normal de Caetano de Campos com aquela monárquica. Para ele, o período que se segue ao advento da República foi marcado, como era de se esperar, pelo que Bourget denomina "poesia da Revolução", "pensamento que não admite a possibilidade de progresso senão pela ruptura com a tradição", e que se fez necessário naquela época para galvanizar as vontades dos educadores. Ele produziu, entretanto, com ilações precipitadas sobre o desamor do império pela educação, a formação de uma lenda. Assim, atribuir as conquistas da Escola Normal exclusivamente aos progressos recentes seria um erro e uma injustiça, pois se a Escola Normal monárquica não tinha grandes recursos didáticos, tinha grandes professores (de real prestígio pelo saber e grande autoridade moral) que foram influência inspiradora para a mocidade de então.

\section{A mordaça escolar entre a "Ordem e (o) Progresso": as "novas" propostas para o ensino e a "Escola sem Partido"}

Se, como mostrado acima, o primeiro decênio da República fora sempre relembrado com nostalgia pelos educadores da época como "período áureo", em razão da esperança de um futuro melhor com o avanço da ciência e da escolarização dos povos, os anos que abrem a segunda década do novo século já são considerados, para muitos, como os anos do pesadelo brasileiro. Uma mudança repentina, mas anunciada, na condução política do País, tem atingido e, de certa forma, desmontado, como um tsunami, a maioria das políticas públicas brasileiras e, dentre elas, as de educação. Com o lema da "Ordem e Progresso", mudanças em andamento como a propalada "Reforma do Ensino Médio", um conjunto de diretrizes que prevê alterações substanciais na grade curricular e na carga horária dos cursos, além de estímulos à formação técnica e tecnicista dos estudantes que foi aprovado recentemente, trazem insegurança e grande preocupação; apesar de ter se dado sem consulta e de forma impositiva ao conjunto dos atores envolvidos com a educação brasileira, a reforma regressiva segue a passos rápidos para sua consolidação no conjunto de diretrizes estipuladas pela LDBEN (Lei de Diretrizes e Bases da Educação Nacional 9394) de 1996, incluindo, aqui, uma "nova" Base Curricular para a Educação Básica. Segundo entidades de classe e do conjunto de especialistas e pesquisadores do campo educacional, com essa reforma o "futuro dos estudantes é incertos"

\footnotetext{
5 Disponível em: http://www.anped.org.br/news/reforma-do-ensino-medio-entenda-o-que-esta-em-jogo-evozes-desconsideradas-no-processo. Acesso em 05.jul.2017.
} 
Ao que parece, vive-se, mais do que uma era de incertezas, uma era de retrocessos e regressões no campo das relações políticas e da própria política que, esvaziada de sentido crítico e de responsabilidade social pelo coletivo dos cidadãos, tem como mira seu arauto maior e grande campo de exercício das lutas ideológicas que é, justamente, a educação das massas. É como se não sobrasse a mínima sombra daquilo que se quis demonstrar naqueles tempos em que se sonhava com um povo e uma nação iluminados pelo sol da ciência. No lugar desta, cabe restando a técnica que, se foi um dia comparada à arte, hoje indica o procedimento de doutrinação das grandes massas e de uma parte dos cientistas para a produção e reprodução utilitária da existência humana, esvaziada do sentido liberador, libertador e emancipador.

Para além de uma ruptura com o passado, pretende-se, com a proposta de Reforma do ensino Médio e com a "nova" Base Nacional Comum Curricular para a Educação Básica (BNCC), um retorno a bases a-históricas e a-políticas da Educação, um retorno a tempos remotos onde se buscava, simplesmente, "o controle e a mercantilização do conhecimento, bem como a regulamentação sobre os discursos pedagógicos" (ANDES, 2016). Pela proposta de reforma da educação básica defendida atualmente pelo Ministério da Educação do Brasil, com a existência de um currículo comum e igual para todo o território nacional "desconsidera (-se) as diferenças regionais e impede a autonomia do professor na definição de conteúdo e seleção de materiais" (idem).

As propostas acima, mesmo que não pareçam num primeiro momento, seguem pari-passu a cartilha de idealizadores de um movimento que tem causado verdadeiros ferimentos de morte numa educação que se pretendia (mesmo sem as condições objetivas mínimas para isso) ensinar os verdadeiros valores da existência. Depois de reformulados e esvaziados de sentido crítico e ideológico, os valores professorais e estudantis podem, finalmente, ser apresentados como "fiéis" ao que se espera de uma educação "sem doutrinação". Falamos aqui, especificamente da "Escola sem Partido", movimento que se autointitula defender os pais daqueles professores "comprometidos com uma visão unilateral, preconceituosa ou tendenciosa das questões políticas e sociais" ou engajados "na execução de um projeto de engenharia social, que supõe a implementação de uma nova escala de valores", conforme se pode verificar na página de apresentação do movimento ${ }^{6}$, buscando impor uma espécie de "mordaça" aos profissionais da educação comprometidos com mudanças estruturais tão necessárias e imprescindíveis ao povo e à nação brasileiros.

Para os ideólogos da bandeira de uma Escola sem Partidos, ela mesma partidária de uma escola e de uma educação sem qualidades ou sem quaisquer possibilidades de intervenção na triste realidade do país, "a pretexto de transmitir aos alunos uma "visão crítica" da realidade, um exército organizado de militantes travestidos de professores prevalece-se da liberdade de cátedra e da cortina de segredo das salas de aula para impingir-lhes a sua própria visão de mundo (Itálicos nossos)" "7. Para dar cabo de suas expectativas esvaziadas de crítica social (ela mesma indicando um forte viés ideológico de pretensa neutralidade, despolitização e de meritocratismos), dizem lutar: "pela descontaminação $e$ desmonopolização política $e$ ideológica das escolas; pelo respeito à integridade intelectual e moral dos estudantes e pelo respeito ao direito dos pais de dar aos seus filhos a educação moral que esteja de acordo com

\footnotetext{
${ }^{6}$ Disponível em: http://www.escolasempartido.org/apresentacao. Acesso em 05.jul.2017.

${ }^{7}$ Disponível em: http://www.escolasempartido.org/quem-somos. Acesso em 05.jul.2017.
} 
suas próprias convições (sic) (itálicos nossos)" ${ }^{8}$. Uma rápida busca pelo descritor "Paulo Freire" no link de pesquisa do site da "Escola sem Partidos" nos dá uma pequena mostra do que se considera ali como "doutrinação" e "monopólio político e ideológico das escolas", dentre outras questões apontadas como na origem dos problemas dessa escola que, para nós, nem chegou a se realizar totalmente, como já vínhamos apontando no decorrer deste estudo.

O que se pretendeu trazer aqui muito resumidamente neste último caso, ou o da busca, por alguns que se traduzem em paladinos da educação moral e de resgate dos valores tradicionais perdidos em algum momento de outrora, de uma escola que se traduz na impossibilidade de se juntar a outras áreas da vida pública e de outros campos da disputa ideológica por um País diferente deste, foi justamente isso: esse movimento espiralado que ora declina e regride e que parece retornar a fontes primordiais, quando o ensino de ler, escrever e contar era o que se requeria ao povo não culto e não domesticado pelas letras de um saber monótono, enfadonho e instrumental, que serve às elites dominantes para a manutenção do próprio status quo.

\section{Considerações Finais}

A presença das metáforas educacionais para definir o trabalho e a carreira docente nos discursos veiculados pela Revista de Ensino mostra a ambiguidade como marca constitutiva do pensamento da época sobre essas questões. Assim se encontramos nesse periódico discursos que condenam os baixos salários e as condições precárias de muitas escolas, tais metáforas, especialmente aquelas tributárias da religião, sugerem a aceitação dos fatos e manutenção do entusiasmo pelos professores, tendo em vista a "santidade" desse "sacerdócio". Além disso, elas ligam-se diretamente ao civismo, pois a principal "missão" do professor era a formação do caráter dos alunos, entendida como formação moral do "bom cidadão" e da "boa mãe". Por outro lado, a boa atuação do professor era associada aos métodos de ensino por ele utilizado. Aqui surgia o recurso à ciência como o principal argumento discursivo: paradoxalmente, um "mau método" não era aquele obstativo do êxito, e sim o não fundamentado em "novos conhecimentos científicos". Tudo isso fazia os debates sobre o progresso do país caracterizarem-se pela dualidade filiando-se a duas vertentes distintas: ora dependente da consolidação de um maior civismo, ora da disseminação de práticas ditas científicas.

Podemos perceber que os discursos publicados nos desvelam, na constituição do campo educacional paulista, as inter-relações entre poder e saber. O recurso à utilização de novos conhecimentos científicos para embasar as práticas docentes permitiria conferir, aos professores, identidade como grupo e novo prestígio social - no período, ciência e progresso aparecem como elementos indissociáveis. A posse de mais ou menos conhecimentos científicos também cria distinções entre os próprios educadores. A insistência na publicação desses discursos, por outro lado, indica a presença de tensões nesse campo em formação: se essas justificativas garantissem a adoção de novos métodos de ensino pela maioria do professorado, não haveria necessidade de tais discursos (quase todos exortativos), tampouco de sua publicação. Afinal, o recurso à ciência para a constituição da pretendida identidade progressista do professorado paulista desqualificava o trabalho de todos os professores que, fosse por vicissitudes da formação, fosse por convicção, não empregavam os métodos recomendados pela Revista de Ensino.

\footnotetext{
${ }^{8}$ Disponível em: http://www.escolasempartido.org/objetivos. Acesso em 05.jul.2017.
} 
Nos dias atuais, percebe-se uma dualidade semelhante aquela presente nas páginas da Revista de Ensino em um discurso que busca esvaziar as práticas de ensino de toda e qualquer característica política, que desloca mais uma vez a eficácia do ensino às características morais do professor e que desconsidera sobremaneira toda a história de luta pela democratização do saber (racional, científico e político) e profissionalização da carreira docente.

\section{Referências}

ANDES - Sindicato Nacional dos Docentes das Instituições de Ensino Superior. Nota política do ANDES-SN sobre a Base Nacional Comum Curricular (BNCC). Disponível em: http://portal.andes.org.br/imprensa/noticias/imp-ult-2053556448.pdf. Acesso em 29 jun.2018.

BITTENCOURT, Circe. “As ‘Tradições Nacionais' e o Ritual das Festas Cívicas” In: PINSKY, Jaime, NADAI, Elsa et al. O ensino de história e a criação do fato. São Paulo: Contexto, 1988, p. 43-73.

CARVAlHO, Marta Maria Chagas de. A escola e a República. São Paulo: Ed. Brasiliense: 1989, $1^{\circ}$ ed., Col. Tudo é História, 87p.

CATANI, Denice Barbara. Educadores à meia luz: um estudo sobre a Revista de Ensino da Associação Beneficente do Professorado Público de São Paulo. Tese de doutoramento apresentada à Faculdade de Educação da Universidade de São Paulo. São Paulo, 1989.

FERNANDES, Rogério. "Ofício de professor: o fim e o começo dos paradigmas" In: SOUZA, Cynthia, CATANI, Denice Barbara (orgs.) Práticas Educativas, Culturas Escolares, Profissão Docente. SP: Escrituras, 1998, p.1-20.

FOUCAULT, Michel. Vigiar e Punir. Petrópolis:Vozes, 1984, $3^{\text {a }}$ ed.

GONDRA, José Gonçalves. "Medicina, Higiene e educação Escolar”. In: LOPES, Eliana Marta Teixeira; FARIA FILHO, Luciano Mendes \& VEIGA, Cynthia Greive. (orgs.). 500 anos de educação no Brasil. Belo Horizonte: Autêntica: 2000, p. 519-550.

NÓVOA, A. “A imprensa de educação e ensino”. In: CATANI, Denice Barbara e BASTOS, Maria Helena Câmara (orgs). Educação em Revista - A imprensa periódica e a História da Educação. São Paulo: Escrituras, 1997, p. 11-31.

SCHEFFLER, Israel. A Linguagem da Educação. SP: EDUSP/Saraiva, 1974.

SOUZA, Rosa Fátima de. "Rituais escolares: liturgia cívica e glorificação da memória (aproximações históricas)". In: PORTO, SANCHEZ TEIXEIRA, FERREIRA SANTOS \& BANDEIRA (orgs.). Tessituras do Imaginário: cultura \& educação.Cuiabá: Edunic/CICE/FEUSP, 2000, p.173-184. 


\section{Fontes}

Revista de Ensino (1902-1918) - Discursos

ARANHA, Antônio Alves, Revista de Ensino, março de 1904.

ARANHA, Antônio Alves, Revista de Ensino, junho de 1907.

BREVES, Arthur, Revista de Ensino, agosto de 1904.

BRISOLLA, Oscar, Revista de Ensino, dezembro de 1915.

BUENO, Dino, Revista de Ensino, março de 1906.

CARDIM, Carlos A. Gomes, Revista de Ensino, março de 1908.

DORDAL, Ramon Roca, Revista de Ensino, dezembro de 1911.

ESCOBAR, Carlos, Revista de Ensino, setembro de 1911.

GONZALEZ, Luiz Felipe, Revista de Ensino, junho de 1914.

KOPKE, João, Revista de Ensino, março de 1910.

KUHLMANN, Guilherme, Revista de Ensino, dezembro de 1914.

MANDELLI, Mario, Revista de Ensino, dezembro de 1916.

MORAIS, Theodoro de, Revista de Ensino, dezembro de 1911.

NACARADO, Paulina, Revista de Ensino, março de 1908.

NASCIMENTO, Alfredo, Revista de Ensino, dezembro de 1903 e fevereiro de 1904.

NETO, Coelho, Revista de Ensino, março de 1916.

OLIVEIRA, José Feliciano de, Revista de Ensino, fevereiro de 1903, p. 1101- 1111

REIS, Maria, Revista de Ensino, novembro de 1907.

RODRIGUES, João Lourenço, Revista de Ensino, junho de 1904, setembro de 1907 e março de 1914. 